\title{
Survival Benefit of Intraductal Radiofrequency Ablation for Malignant Biliary Obstruction: A Systematic Review with Meta- Analysis
}

\author{
Byung Hyo Cha ${ }^{1 *}$, Myoung-Jin Jang ${ }^{2 *}$ and Sang Hyub Lee ${ }^{3}$ \\ ${ }^{1}$ Division of Internal Medicine, Sheikh Khalifa Specialty Hospital, Ras Al Khaimah, United Arab Emirates, ${ }^{2}$ Medical Research Collaborating \\ Center, Seoul National University Hospital, Seoul National University College of Medicine, Seoul, Korea, ${ }^{3}$ Department of Internal Medicine, \\ Seoul National University Hospital, Seoul National University College of Medicine, Seoul, Korea
}

Background/Aims: Cholangiocarcinoma (CCA) is a rare but aggressive disease with a poor survival. Recent trials have shown improved survival with intraductal radiofrequency ablation (RFA) therapy. We performed a systematic review with meta-analysis to determine the survival benefit of endoscopic RFA for unresectable extrahepatic CCA with malignant biliary obstruction (MBO). Methods: A systematic search from 1970 to 2020 was performed in MEDLINE, EMBASE, Cochrane Library, and ClinicalTrials. gov. We selected eligible studies reporting relative risks, hazard ratios (HRs), or odds ratios, adjusted by controlling for confounding factors of survival rate and stent patency duration, among patients with extrahepatic CCA with MBO treated with RFA with stent insertion or stent insertion only.

Results: A total of eight trials (three randomized and five nonrandomized) with a total of 420 patients were included in the metaanalysis. Pooled overall survival analysis favored RFA treatment with stent insertion (HR, 0.47; 95\% confidence interval [CI], 0.34$0.64 ; I^{2}=47 \% ; p=0.09$ ); however, no significant difference was found in the duration of stent patency between the groups (HR, 0.79 ; 95\% CI, $0.57-1.09 ; I^{2}=7 \%$; $p=0.36$ ).

Conclusions: RFA therapy with stent insertion may confer a survival benefit compared with stent insertion only in patients with CCA and MBO. Clin Endosc 2021;54:100-106

Key Words: Cholangiocarcinoma; Malignant biliary obstruction; Meta-analysis; Radiofrequency ablation; Survival rates

\section{INTRODUCTION}

Cholangiocarcinoma (CCA) is an uncommon, aggressive, malignant disease with a poor prognosis. It accounts for $3 \%$ of all gastrointestinal malignancies. ${ }^{1,2}$ The overall incidence from 2001 to 2015 was 1.26 per 100,000 people per year in

Received: September 16, 2020 Revised: October 15, 2020

Accepted: October 27, 2020

Correspondence: Byung Hyo Cha

Division of Internal Medicine, Department of Gastroenterology, Sheikh Khalifa Specialty Hospital, Al Shohadaa Road, Ras Al Khaimah, United Arab Emirates Tel: +971-7-201-1412, Fax: +971-7-203-2222, E-mail: doctorhyo@gmail.com ORCID: https://orcid.org/0000-0002-1770-1722

*These authors contributed equally to this study.

(c) This is an Open Access article distributed under the terms of the Creative Commons Attribution Non-Commercial License (http://creativecommons.org/ licenses/by-nc/3.0) which permits unrestricted non-commercial use, distribution, and reproduction in any medium, provided the original work is properly cited. the United States. ${ }^{3}$ CCA can be classified into three categories according to anatomical location: intrahepatic, perihilar, and distal CCA. Perihilar CCA accounts for 60\%, distal CCA accounts for $30 \%$, and intrahepatic CCA accounts for the remaining $10 \%$ of the cases. The prognosis of patients with CCA is poorer than that of patients with other malignant diseases of the gastrointestinal tract. The mortality rate is high because of late diagnosis and limited chances for curative surgery, and the resection rate at the initial diagnosis has been reported to be $20 \%-30 \%$. ${ }^{4,5}$ In a previous prospective study of inoperable cases, the 1- and 2-year overall survival rates of CCA were $22.4 \%$ and $3.4 \%$, respectively. ${ }^{6}$

For a long time, metallic or plastic biliary stenting has been considered the best palliative treatment for unresectable CCA or malignant biliary obstruction (MBO) caused by pancreatic cancer. However, several attempts have been recently made to improve clinical outcomes using local tumor treatments. 
Radiofrequency ablation (RFA) is a regional direct tumor ablation treatment for unresectable CCA or MBO due to metastatic biliary tumors, in which radiofrequency energy is delivered through endoscope channels. This technique has yielded outstanding outcomes in some prospective studies over the last decade. ${ }^{7.8}$ Therefore, the aim of this meta-analysis and systematic review was to determine the effect of endobiliary RFA therapy on the survival outcome of patients with unresectable extrahepatic CCA with $\mathrm{MBO}$.

\section{MATERIALS AND METHODS}

\section{Search methods for identification of studies}

A systematic review of published articles from 1970 through 2020 was conducted by searching MEDLINE, EMBASE, Cochrane Library, and ClinicalTrials.gov. Selection was restricted to studies written in English. The keywords used to search for relevant articles in the different databases are described in Appendix 1. References listed in the retrieved articles were reviewed for eligible studies.

\section{Article selection}

Eligible studies were determined according to the following criteria: (1) studies that analyzed patients with extrahepatic CCA or MBO, (2) studies that compared treatment outcomes between endobiliary RFA with stent insertion and stent insertion only, (3) randomized controlled trials (RCTs) and casecontrol studies with adjustment for confounding variables, and (4) studies reporting the relative risks or odds ratios of survival rate and stent patency duration in an RFA with stent group and a stent-only group.

\section{Data extraction}

The following information was extracted from each article: publication year, country, study design, case number, age of patients, sex of patients, presence of gallstones, tumor-node-metastasis stages, treatment methods, surgical outcomes, and survival times. Covariates were adjusted for in the statistical analysis. Among several case series reports, we extracted the same data from each case reference.

\section{Assessment of risk of bias}

The risk of bias (RoB) was independently assessed by two reviewers (BHC and MJJ) using the Cochrane RoB Tool for RCTs $^{9}$ and ROBINS-I (RoB in Nonrandomized Studies [NRSs] of Interventions) for NRSs. ${ }^{10}$ The RoB for RCTs was graded as "low" for low risk, "high" for high risk, and "unclear" when the available information was not sufficient for a risk judgment. For NRSs, each domain of the RoB was rated as "low", "mod- erate", "serious", or "critical" for RoB, and the overall RoB was determined according to the judgment for each domain. Any disagreements between the reviewers were resolved through a discussion among the three authors.

\section{Quality of included studies}

Among the RCTs, two studies (Yang et al. ${ }^{7}$ and Kang et al. ${ }^{11}$ ) were rated as low for all RoB domains, whereas the other study (Hu et al. ${ }^{8}$ ) was rated as low for two domains (random sequence generation and incomplete outcome data) and as unclear for the other domains. All five $\mathrm{NRSs}^{12-16}$ were graded as having an overall moderate RoB. In the domain of RoB due to confounding, four studies ${ }^{12-15}$ used matching for confounding adjustment and one study ${ }^{16}$ showed similar distributions of confounding covariates between groups. The RoB for this item was rated as moderate. The other RoB items were graded as low (Appendix 2).

\section{Statistical analysis}

The effects of treatments (RFA plus stent vs. stent only) on overall survival and stent patency were examined on the basis of pooled hazard ratios (HRs) and corresponding 95\% confidence intervals (CIs). The HRs and 95\% CIs for these outcomes were extracted from the results of each study, or estimated based on available information such as log-rank test results and Kaplan-Meier curves. ${ }^{17}$ Pooled HRs among studies and their 95\% CIs and $p$-values were calculated using the random-effect model. Statistical heterogeneity between the studies was assessed using Cochran's Q-test and $I^{2}$ statistics. $I^{2}$ values of $25 \%, 50 \%$, and $75 \%$ were considered to indicate low, moderate, and high heterogeneity, respectively, as previously suggested. ${ }^{18} \mathrm{~A}$ funnel plot and Egger's test for asymmetry were applied to assess the possibility of publication bias among the studies for overall survival, but not for stent patency because of the small number of included studies. All analyses were performed using R version 3.5.1 (meta package). Two-sided $p$-values of $<0.05$ were considered statistically significant.

\section{RESULTS}

A total of 631 articles were reviewed for eligibility, and 600 studies were excluded according to criteria (Fig. 1). Among 31 eligible studies, we selected 3 RCTs and 5 retrospective trials that reported HRs adjusted for various confounding factors (3 case-control and 2 observational studies). Therefore, a total of eight studies with 420 participants (190 cases treated with RFA plus stent and 230 controls treated with stent insertion only) were included in the meta-analysis. The baseline descriptions of all enrolled studies are listed in Table 1. The most common 


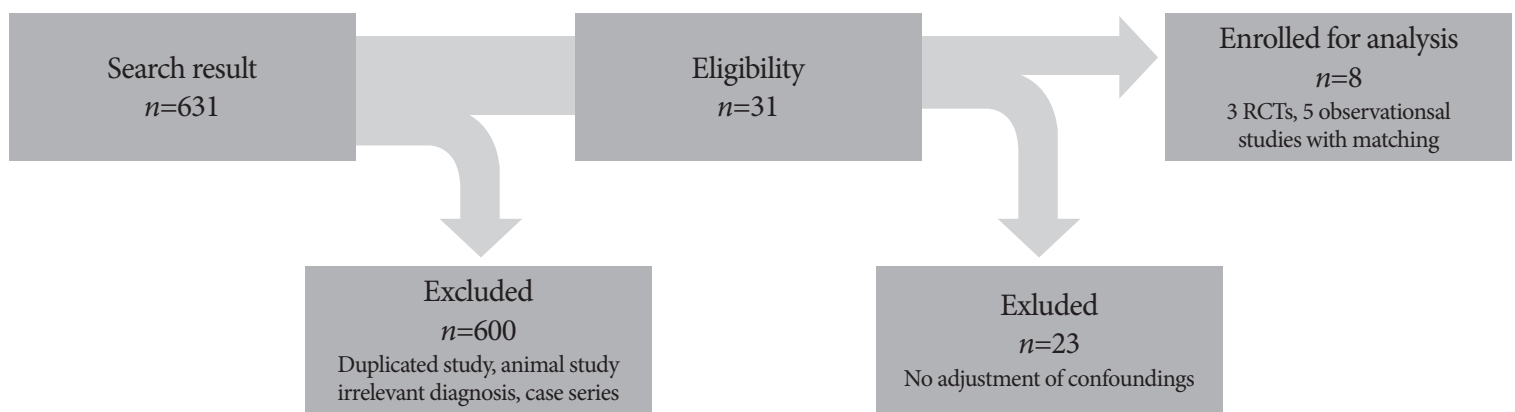

Fig. 1. Schematic flowchart of study enrollment, including identification, screening, eligibility, exclusion, and analysis inclusion, according to Preferred Reporting Items for Systematic Reviews and Meta-analyses (PRISMA) guidelines 2009. RCTs, randomized controlled trials.

Table 1. Summarized Study Designs, Outcomes and Adverse Events among the Eight Enrolled Studies

\begin{tabular}{|c|c|c|c|c|c|c|c|c|}
\hline \multirow{2}{*}{ Study } & \multirow{2}{*}{ Study design } & \multicolumn{2}{|c|}{ No. of patients } & \multirow{2}{*}{ Outcome } & \multicolumn{2}{|c|}{ Median time (95\% CI, mo) } & \multirow{2}{*}{$\begin{array}{c}\text { HR }(95 \% \mathrm{CI}) \text { for } \\
\text { RFA }\end{array}$} & \multirow{2}{*}{ Adverse events } \\
\hline & & $\mathrm{RFA}+\mathrm{S}$ & Stent & & $\mathrm{RFA}+\mathrm{S}$ & Stent & & \\
\hline Sharaiha et al. $(2014)^{12}$ & Retrospective & 26 & 40 & $\begin{array}{l}\text { Overall } \\
\text { survival }\end{array}$ & $\begin{array}{l}5.9 \text { for both gr } \\
\text { ported for e }\end{array}$ & $\begin{array}{l}\text { oups (not re- } \\
\text { ach group) }\end{array}$ & $0.29(0.11-0.76)$ & $\begin{array}{c}\text { Abdominal pain } \\
\text { 3; Pancreatitis 1; } \\
\text { Cholecystitis 1 }\end{array}$ \\
\hline \multirow[t]{2}{*}{ Kallis et al. $(2015)^{13}$} & Retrospective & 23 & 46 & $\begin{array}{l}\text { Overall } \\
\text { survival }\end{array}$ & 7.5 & 4.1 & $0.66(0.410-1.063)$ & \multirow{2}{*}{$\begin{array}{l}\text { Hyperamylase- } \\
\text { mia 1; Cholangi- } \\
\text { tis } 1\end{array}$} \\
\hline & & & & $\begin{array}{c}\text { Stent } \\
\text { patency }\end{array}$ & 15.7 & 10.8 & $\begin{array}{c}1.186(0.536- \\
2.656)\end{array}$ & \\
\hline \multirow[t]{2}{*}{ Hu et al. $(2016)^{8}$} & RCT & 32 & 31 & $\begin{array}{l}\text { Overall } \\
\text { survival }\end{array}$ & $10.4(8.0-12.7)$ & $57.3(4.8-6.6)$ & $0.48(0.27-0.85)^{\mathrm{a})}$ & \multirow{2}{*}{$\begin{array}{c}\text { Bleeding 1; } \\
\text { Cholangitis 20; } \\
\text { Cholecystitis } 7\end{array}$} \\
\hline & & & & $\begin{array}{c}\text { Stent } \\
\text { patency }\end{array}$ & $5(3.0-7.1)$ & $3.9(2.6-5.2)$ & $0.90(0.52-1.55)^{\mathrm{a})}$ & \\
\hline \multirow[t]{2}{*}{ Wang et al. $(2016)^{14}$} & Retrospective & 18 & 18 & $\begin{array}{l}\text { Overall } \\
\text { survival }\end{array}$ & $6.1(4.8-15.2)$ & $5.8(4.2-16.5)$ & $\begin{array}{c}0.598(0.324- \\
1.324)\end{array}$ & \multirow[t]{2}{*}{ Cholangitis 3} \\
\hline & & & & $\begin{array}{c}\text { Stent } \\
\text { patency }\end{array}$ & $5.8(2.8-11.5)$ & $4.5(2.4-8.0)$ & $0.49(0.25-0.93)^{\mathrm{a})}$ & \\
\hline Dutta et al. $(2017)^{15}$ & Retrospective & 15 & 16 & $\begin{array}{l}\text { Overall } \\
\text { survival }\end{array}$ & 7.3 & 4.9 & $0.39(0.17-0.92)$ & $\begin{array}{l}\text { Pancreatitis 1; } \\
\text { Cholangitis } 1\end{array}$ \\
\hline \multirow[t]{2}{*}{ Yang et al. $(2018)^{7}$} & RCT & 32 & 33 & $\begin{array}{l}\text { Overall } \\
\text { survival }\end{array}$ & $13.2 \pm 0.6^{\mathrm{b})}$ & $8.2 \pm 0.5^{\mathrm{b})}$ & $0.182(0.08-0.322)$ & \multirow[t]{2}{*}{ Cholangitis 2} \\
\hline & & & & $\begin{array}{c}\text { Stent } \\
\text { patency }\end{array}$ & $6.8(3.6-8.2)$ & $3.4(2.4-6.5)$ & $N / A^{c)}$ & \\
\hline $\begin{array}{l}\text { Bokemeyer et al. } \\
(2019)^{16}\end{array}$ & Retrospective & 20 & 22 & $\begin{array}{l}\text { Overall } \\
\text { survival }\end{array}$ & 11.4 & 7.4 & $0.54(0.29-0.99)^{\mathrm{a})}$ & $\begin{array}{l}\text { Cholangitis 6; } \\
\text { panceratitis } 2 \text {; } \\
\text { Intestinal perfo- } \\
\quad \text { ration } 1^{\mathrm{d})}\end{array}$ \\
\hline \multirow[t]{2}{*}{ Kang et al. $(2021)^{11}$} & RCT & 24 & 24 & $\begin{array}{l}\text { Overall } \\
\text { survival }\end{array}$ & $8.3(3.9-12.3)$ & $6.0(0.9-11.1)$ & $0.71(0.38-1.33)$ & \multirow[t]{2}{*}{ Cholangitis 1} \\
\hline & & & & $\begin{array}{c}\text { Stent } \\
\text { patency }\end{array}$ & $4.4(3.3-5.5)$ & $3.9(1.1-5.9)$ & $0.80(0.45-1.42)$ & \\
\hline
\end{tabular}

CI, confidence interval; HR, hazard ratio; N/A, not available; RCT, randomized controlled study; RFA, radiofrequency ablation; RFA+S, radiofrequency ablation plus stent.

${ }^{a} \mathrm{HR}$ calculated from a log-rank $p$-value and number of event.

${ }^{\text {b) }}$ Mean survival time \pm standard error.

${ }^{c}$ Information not available for estimation of $\mathrm{HR}$.

${ }^{\mathrm{d})}$ One intestinal perforation with pneumothorax occurred in one study, however, authors commented that it was not related with RFA procedure, rather than by the scope device. 
tumor site was the extrahepatic bile duct (61.8\%, hilar and distal CCA). Pancreatic cancer, gallbladder cancer, and metastatic biliary cancer accounted for $33.7 \%, 2.2 \%$, and $1.2 \%$, respectively. All studies involved ablation with endoscopic retrograde cholangiopancreatography (ERCP), except for the study by Wang et al., which used the percutaneous transhepatic route. ${ }^{14}$ For RFA treatment, six of the enrolled studies mentioned using the same thermal probe (e.g., Habib probe) from the same manufacturer; however, one study ${ }^{11}$ used the ELRA ${ }^{\mathrm{TM}}$ (EndoLuminal Radiofrequency Ablation; Taewoong Medical, Seoul, Korea) probe and $\mathrm{Hu}$ et al. ${ }^{8}$ did not describe the RFA devices in detail. Differences were noted in the type of stent used in each study after RFA. Two RCTs inserted only plastic stents, ${ }^{7,8}$ another study ${ }^{11}$ inserted self-expandable metallic stents (SEMSs), whereas all retrospective trials used SEMSs in most of their cases. ${ }^{12-16}$

The pooled HR for overall survival in the case group treated with RFA with stent was 0.47 (95\% CI, 0.34-0.64; Fig. 2). A moderate heterogeneity was detected among the included studies $\left(I^{2}=44 \%\right)$. Only four articles (two RCTs and two observational studies) reported stent patency results. The pooled HR for stent patency was 0.79 (0.57-1.09), with a low heterogeneity $\left(I^{2}=7 \%\right.$; Fig. 3$)$. All included studies reported mild-to-moderate adverse reaction profiles among their case groups.

Abdominal pain (3 cases), pancreatitis and hyperamylasemia (3 cases), cholangitis regardless of symptoms (34 cases), and cholecystitis (8 cases) were reported. All these complications were treated with antibiotics and conservative therapy, and no procedure-related mortality was reported. One case of intestinal perforation with pneumothorax occurred in one study; however, the authors commented that it was not related to the RFA procedure but rather to the scope device. No study demonstrated significant differences in terms of adverse events between the RFA plus stent group and the stent-only group. No significant publication bias was noted in the funnel plot for overall survival (Egger's test $p=0.2869$; Fig. 4 ).

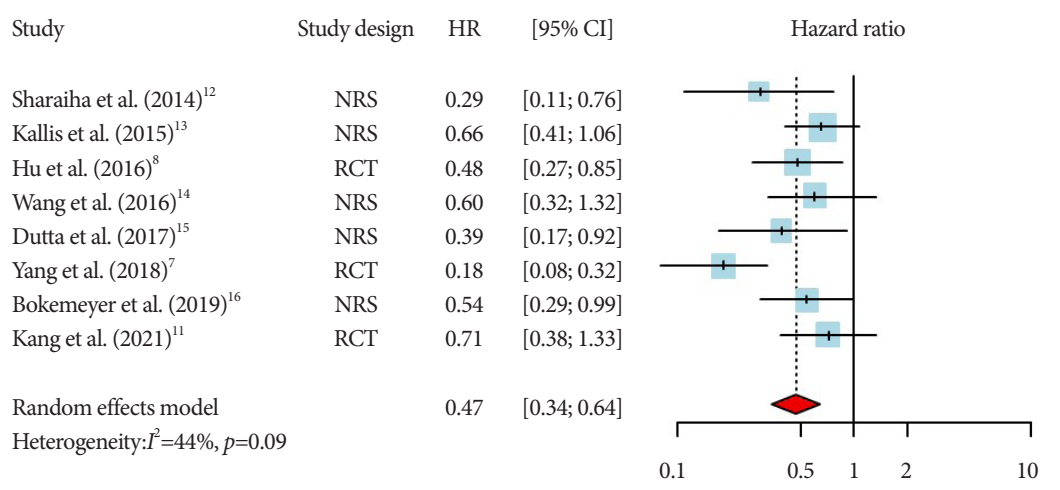

Fig. 2. Pooled hazard ratios (HRs) and corresponding $95 \%$ confidence intervals $(\mathrm{Cls})$ of overall survival rates between two groups (endobiliary radiofrequency ablation with stent vs. stent only) among patients with cholangiocarcinoma with malignant biliary obstruction (random-effect model, eight studies with 420 participants). NRS, non-randomised study; RCT, randomized controlled trial.

$\begin{array}{lccc}\text { Study } & \text { Study design } & \text { HR } & {[95 \% \mathrm{CI}]} \\ \text { Kallis et al. }(2015)^{13} & \text { NRS } & 1.19 & {[0.54 ; 2.66]} \\ \text { Hu et al. }(2016)^{8} & \text { RCT } & 0.90 & {[0.52 ; 1.55]} \\ \text { Wang et al. }(2016)^{14} & \text { NRS } & 0.49 & {[0.25 ; 0.93]} \\ \text { Kang et al. }(2021)^{11} & \text { RCT } & 0.80 & {[0.45 ; 1.42]} \\ & & & \\ \text { Random effects model } & & 0.79 & {[0.57 ; 1.09]} \\ \text { Heterogeneity: } I^{2}=7 \%, p=0.36 & & & \end{array}$

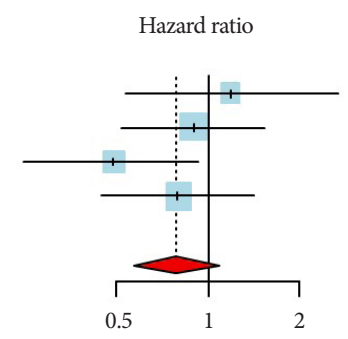

Fig. 3. Pooled hazard ratios (HRs) and corresponding 95\% confidence intervals (Cls) of stent patency between two groups (endobiliary radiofrequency ablation with stent vs. stent only) among patients with cholangiocarcinoma with malignant biliary obstruction (random-effect model, four studies with 205 participants). NRS, non-randomised study; RCT, randomized controlled trial. 


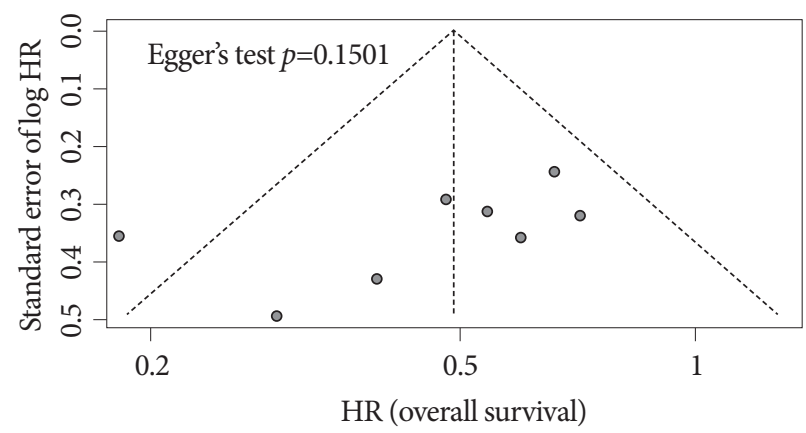

Fig. 4. Funnel plot and Egger's test for asymmetry for survival outcome analyses of eight enrolled studies. HR, hazard ratio.

\section{DISCUSSION}

Although CCA is not a common malignant disease, the clinical outcomes are poor and the mortality rate is high because it is usually detected in an advanced stage at diagnosis. Surgical resection can provide the best curative treatment; however, most cases are unresectable or are poor candidates for surgery. Various types, designs, compositions, and sizes of stents have been developed; however, no survival improvement has been reported, except for the observation that stents with larger diameters may have a longer patency duration. ${ }^{19}$ In this context, researchers have introduced many local treatments, including RFA and photodynamic therapy for $\mathrm{MBO}$ for the palliative treatment of advanced CCA.

RFA is a locoregional cancer treatment that delivers thermal energy generated by high-frequency alternating electrical current; however, it causes burn injuries that lead to protein denaturation, cell desiccation, and coagulative necrosis. ${ }^{20}$ Two types of thin probe catheters have been introduced for endobiliary RFA treatment through ERCP scope channels: Habib EndoHPB (EMcision Ltd., London, UK; Boston Scientific, Marlborough, MA, USA) and ELRA ${ }^{\mathrm{TM}}$ (Taewoong Medical). Since the first human study that reported successful decompression of bile duct obstruction, ${ }^{21}$ this therapy has been considered a palliative treatment for unresectable cases with MBO. However, some studies during the last decade reported that this challenging therapy enhanced not only the patency of the biliary tract but also the survival times of patients. These promising data suggest that sustained bile duct patency could prolong survival in patients with $\mathrm{MBO}$. We investigated the clinical outcomes of local ablative treatment for MBO by performing a meta-analysis of eight clinical studies. We observed a survival benefit among patients who were treated with RFA with stent insertion compared with the stent-only group.
The mechanism of the survival benefit of this local ablation treatment may be explained by its ability to relieve biliary obstruction and prevent recurrent cholangitis, the leading cause of mortality. However, we found two interesting features from the enrolled articles. First, the results of Kallis et al. showed that stent patency was better in the stent-only group than in the RFA with stent group; however, the overall survival rate of the RFA with stent group was superior to that of the other group. ${ }^{13}$ Sharaiha et al. found a survival improvement after adjustment for confounding factors, including stricture improvement. ${ }^{12}$ Although data supporting this phenomenon are insufficient, these results suggest that mechanisms other than stent patency improve survival outcomes. Other research data in various solid tumor treatments support this hypothesis. Hansler et al. reported on the tumor-specific cytolytic activity of CD8(+) T cells after RFA therapy in patients with hepatocellular carcinoma and colorectal liver metastasis, suggesting that RFA may play a role through indirect anti-tumor effects. ${ }^{22}$ den Brok et al. found that in situ tumor destruction provided a useful antigen source for the induction of antitumor immunity. $^{23}$

In terms of adverse events, we confirmed no serious perioperative or postoperative complications in our enrolled studies, except for mild-to-moderate cholangitis, pancreatitis, and a few cases of cholecystitis, all of which were medically treated. Nevertheless, there have been a few reports of critical adverse events in other retrospective studies. Tal et al. reported two deaths due to hemobilia, and thereby suggested insertion of SEMSs after RFA instead of plastic stents. ${ }^{24}$ Roque et al. emphasized that a 1-min delay in removing the probe after RFA ablation to prevent tissue adhesion caused by heated electrodes might be a cause of tissue or vascular injury, possibly leading to hemobilia during withdrawal, ${ }^{25}$ citing the study method described by Dolak et al. ${ }^{26}$ One rare case of liver infarction after treatment, which was conservatively managed, was also reported. ${ }^{25}$ The authors recommended performing more careful preprocedural imaging analysis to avoid vascular or biliary injury. ${ }^{26}$

Few studies with higher evidence levels and that explored the relationship between RFA treatment and survival improvement in patients with CCA are available. The number of studies included in our systematic review was very small: the pooled analysis for overall survival was performed using eight studies (three RCTs and five observational studies), and stent patency was reported in only four of these studies. Moreover, all our enrolled studies included a considerable number of patients with pancreatic cancer and gallbladder cancer with biliary invasion, although the proportions were not high. The survival benefit should be compared in different ways because 
different primary cancer sites would cause different clinical outcomes. However, we could not compare the pooled HRs because the original studies did not report the data for each subgroup. In this regard, further studies with subgroup analysis in terms of different primary cancer origins are warranted in the future.

Despite these limitations, our systematic review with meta-analysis, of three RCTs and five retrospective studies with control for confounding factors, demonstrates that endobiliary RFA treatment confers a survival benefit to patients with $\mathrm{MBO}$ caused by unresectable CCA or pancreatic cancer. More well-designed studies are warranted to elucidate the mechanism of these beneficial effects and to compare the outcomes in various individual primary cancers.

\section{Conflicts of Interest}

The authors have no potential conflicts of interest.

Funding

None.

\section{Author Contributions}

Conceptualization: Byung Hyo Cha, Myoung-Jin Jang

Data curation: $\mathrm{BHC}, \mathrm{MJJ}$

Formal analysis: $\mathrm{BHC}, \mathrm{MJJ}$

Investigation: BHC, MJJ, Sang Hyub Lee

Project administration: BHC

Resources: BHC

Software: BHC, MJ)

Supervision: BHC, SHL

Validation: BHC, MJJ

Visualization: MJJ

Writing-original draft: BHC, MJJ

Writing-review\&editing: BHC, MJJ, SHL

\section{ORCID}

Byung Hyo Cha:

Myoung-jin Jang:

Sang Hyub Lee:

https://orcid.org/0000-0002-1770-1722 https://orcid.org/0000-0001-8123-5001 https://orcid.org/0000-0003-2174-9726

\section{REFERENCES}

1. Vauthey JN, Blumgart LH. Recent advances in the management of cholangiocarcinomas. Semin Liver Dis 1994;14:109-114.

2. Global Burden of Disease Cancer Collaboration; Fitzmaurice C, Dicker D, et al. The global burden of cancer 2013. JAMA Oncol 2015;1:505-527.

3. Patel N, Benipal B. Incidence of cholangiocarcinoma in the USA from 2001 to 2015: A US cancer statistics analysis of 50 states. Cureus 2019;11:e3962.

4. Zografos GN, Farfaras A, Zagouri F, Chrysikos D, Karaliotas K. Cholangiocarcinoma: principles and current trends. Hepatobiliary Pancreat Dis Int 2011;10:10-20.

5. Esnaola NF, Meyer JE, Karachristos A, Maranki JL, Camp ER, Denlinger CS. Evaluation and management of intrahepatic and extrahepatic cholangiocarcinoma. Cancer 2016;122:1349-1369.

6. Mihalache F, Tantau M, Diaconu B, Acalovschi M. Survival and quality of life of cholangiocarcinoma patients: a prospective study over a 4 year period. J Gastrointestin Liver Dis 2010;19:285-290.

7. Yang J, Wang J, Zhou H, et al. Efficacy and safety of endoscopic radiofrequency ablation for unresectable extrahepatic cholangiocarcinoma: a randomized trial. Endoscopy 2018;50:751-760.

8. Hu B, Gao DJ, Zhang X, Zhang YC. Endobiliary radiofrequency ablation improve overall survival of cholangiocarcinoma: a multi-center randomized control study. Gastrointest Endosc 2016;83(5 Suppl):AB126.

9. Higgins JP, Altman DG, Gøtzsche PC, et al. The Cochrane Collaboration's tool for assessing risk of bias in randomised trials. BMJ 2011;343:d5928.

10. Sterne JA, Hernán MA, Reeves BC, et al. ROBINS-I: a tool for assessing risk of bias in non-randomised studies of interventions. BMJ 2016;355:i4919.

11. Kang H, Chung MJ, Cho IR, et al. Efficacy and safety of palliative endobiliary radiofrequency ablation using a novel temperature-controlled catheter for malignant biliary stricture: a single-center prospective randomized phase II TRIAL. Surg Endosc 2021;35:63-73.

12. Sharaiha RZ, Natov N, Glockenberg KS, Widmer J, Gaidhane M, Kahaleh M. Comparison of metal stenting with radiofrequency ablation versus stenting alone for treating malignant biliary strictures: is there an added benefit? Dig Dis Sci 2014;59:3099-3102.

13. Kallis Y, Phillips N, Steel A, et al. Analysis of endoscopic radiofrequency ablation of biliary malignant strictures in pancreatic cancer suggests potential survival benefit. Dig Dis Sci 2015;60:3449-3455.

14. Wang J, Zhao L, Zhou C, et al. Percutaneous intraductal radiofrequency ablation combined with biliary stent placement for nonresectable malignant biliary obstruction improves stent patency but not survival. Medicine (Baltimore) 2016;95:e3329.

15. Dutta AK, Basavaraju U, Sales L, Leeds JS. Radiofrequency ablation for management of malignant biliary obstruction: a single-center experience and review of the literature. Expert Rev Gastroenterol Hepatol 2017;11:779-784

16. Bokemeyer A, Matern P, Bettenworth D, et al. Endoscopic radiofrequency ablation prolongs survival of patients with unresectable hilar cholangiocellular carcinoma - a case-control study. Sci Rep 2019;9:13685.

17. Tierney JF, Stewart LA, Ghersi D, Burdett S, Sydes MR. Practical methods for incorporating summary time-to-event data into meta-analysis. Trials 2007;8:16.

18. Higgins JP, Thompson SG, Deeks JJ, Altman DG. Measuring inconsistency in meta-analyses. BMJ 2003;327:557-560.

19. Loew BJ, Howell DA, Sanders MK, et al. Comparative performance of uncoated, self-expanding metal biliary stents of different designs in 2 diameters: final results of an international multicenter, randomized, controlled trial. Gastrointest Endosc 2009;70:445-453.

20. Goldberg SN, Gazelle GS. Radiofrequency tissue ablation: physical principles and techniques for increasing coagulation necrosis. Hepatogastroenterology 2001;48:359-367.

21. Steel AW, Postgate AJ, Khorsandi S, et al. Endoscopically applied radiofrequency ablation appears to be safe in the treatment of malignant biliary obstruction. Gastrointest Endosc 2011;73:149-153.

22. Hansler J, Wissniowski TT, Schuppan D, et al. Activation and dramatically increased cytolytic activity of tumor specific $\mathrm{T}$ lymphocytes after radio-frequency ablation in patients with hepatocellular carcinoma and colorectal liver metastases. World J Gastroenterol 2006;12:3716-3721.

23. den Brok MH, Sutmuller RP, van der Voort R, et al. In situ tumor ablation creates an antigen source for the generation of antitumor immunity. Cancer Res 2004;64:4024-4029.

24. Tal AO, Vermehren J, Friedrich-Rust M, et al. Intraductal endoscopic radiofrequency ablation for the treatment of hilar non-resectable malignant bile duct obstruction. World J Gastrointest Endosc 2014;6:13-19.

25. Roque J, Ho SH, Reddy N, Goh KL. Endoscopic ablation therapy for biliopancreatic malignancies. Clin Endosc 2015;48:15-19.

26. Dolak W, Schreiber F, Schwaighofer H, et al. Endoscopic radiofrequency ablation for malignant biliary obstruction: a nationwide retrospective study of 84 consecutive applications. Surg Endosc 2014;28:854-860. 


\section{APPENDICES}

Appendix 1. Search key words.

Appendix 2. Quality assessment of risk of bias among the included studies (Tables 1,2).

\section{MEDLINE}

(radiofrequency ablation OR (radiofrequency OR ablation)) AND (cholangiocarcinoma OR ((bile duct OR biliary) AND (cancer OR tumor OR malignancy)) OR (malignant biliary obstruction OR cholestasis))

\section{EMBASE}

*survival; * patient; *human; *bile duct carcinoma; ${ }^{*}$ radiofrequency ablation; therapy; diagnosis; chemoradiotherapy; Kaplan-Meier method; endoscopic retrograde cholangiopancreatography; overall survival; surgery; medical record review; tissue necrosis; randomized controlled trial; retrospective study; survival rate; procedures; biliary stent; distant metastasis; classification; hospital patient; hepatobiliary system

\section{Cochrane Library}

"radiofrequency ablation" in Title Abstract Keyword AND cholangiocarcinoma in Title Abstract Keyword

Table 1. Quality Assessment Using the Cochrane Risk of Bias Tool for Randomized Controlled Trials

\begin{tabular}{lcccccccc}
\hline Study & $\begin{array}{c}\text { Random } \\
\text { sequence } \\
\text { generation }\end{array}$ & $\begin{array}{c}\text { Allocation } \\
\text { conceal- } \\
\text { ment }\end{array}$ & $\begin{array}{c}\text { Blinding of } \\
\text { participants } \\
\text { and personnel }\end{array}$ & $\begin{array}{c}\text { Blinding } \\
\text { of outcome } \\
\text { assessment }\end{array}$ & $\begin{array}{c}\text { Incom- } \\
\text { plete } \\
\text { outcome } \\
\text { data }\end{array}$ & $\begin{array}{c}\text { Selective } \\
\text { reporting }\end{array}$ & $\begin{array}{c}\text { Other sourc- } \\
\text { es of bias }\end{array}$ & $\begin{array}{c}\text { Overall } \\
\text { Hu et al. }(2016)^{8}\end{array}$ \\
Yang et al. $(2018)^{7}$ & Low & Unclear & Unclear & Unclear & Low & Unclear & Unclear & Unclear \\
Kang et al. $(2021)^{11}$ & Low & Low & Low & Low & Low & Low & Low & Low \\
\hline
\end{tabular}

Table 2. Quality Assessment Using Risk of Bias in Nonrandomized Studies of Interventions (ROBINS-I) for Nonrandomized Studies

\begin{tabular}{|c|c|c|c|c|c|c|c|c|}
\hline Study & $\begin{array}{l}\text { Bias due to } \\
\text { confound- } \\
\quad \text { ing }\end{array}$ & $\begin{array}{l}\text { Bias in } \\
\text { selection of } \\
\text { participants } \\
\text { for the study }\end{array}$ & $\begin{array}{l}\text { Bias in mea- } \\
\text { surement of } \\
\text { interventions }\end{array}$ & $\begin{array}{l}\text { Bias due to } \\
\text { departures } \\
\text { from intend- } \\
\text { ed interven- } \\
\text { tions }\end{array}$ & $\begin{array}{c}\text { Bias due } \\
\text { to missing } \\
\text { data }\end{array}$ & $\begin{array}{c}\text { Bias in } \\
\text { measure- } \\
\text { ment of } \\
\text { outcomes }\end{array}$ & $\begin{array}{c}\text { Bias in } \\
\text { selection of } \\
\text { the reported } \\
\text { result }\end{array}$ & Overall \\
\hline Sharaiha et al. $(2014)^{12}$ & Moderate $^{\text {a) }}$ & Low & Low & Low & Low & Low & Low & Moderate \\
\hline Kallis et al. $(2015)^{13}$ & Moderate $^{\mathrm{b})}$ & Low & Low & Low & Low & Low & Low & Moderate \\
\hline Wang et al. $(2016)^{14}$ & Moderate $^{c)}$ & Low & Low & Low & Low & Low & Low & Moderate \\
\hline Dutta et al. $(2017)^{15}$ & Moderate $^{\mathrm{d})}$ & Low & Low & Low & Low & Low & Low & Moderate \\
\hline Bokemeyer et al. $(2019)^{16}$ & Moderate $\left.^{e}\right)$ & Low & Low & Low & Low & Low & Low & Moderate \\
\hline
\end{tabular}

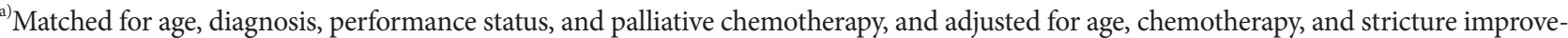
ment.

${ }^{b)}$ Matched for age, sex, comorbidity, American Society of Anesthesiologists category, and presence of metastasis.

${ }^{c)}$ Matched for tumor type, location of obstruction, tumor stage, and Child-Pugh class status.

${ }^{\mathrm{d})}$ Matched for age, sex, disease type, and disease stage, and adjusted for age, tumor site, tumor type, stent type (covered or uncovered), disease stage, and oncological treatment.

${ }^{\text {e) }}$ Similar distributions between groups in terms of age, extent of disease, use of endoprostheses, and application of systemic palliative chemotherapy. 